LEMOS, B.J.M. et al. Suplementação de bovinos de corte em pastejo. PUBVET, Londrina, V. 6, N. 32, Ed. 219, Art. 1457, 2012.

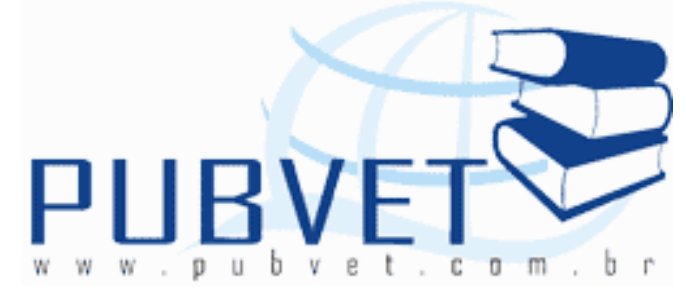

PUBVET, Publicações em Medicina Veterinária e Zootecnia.

\title{
Suplementação de bovinos de corte em pastejo
}

Barbara Juliana Martins Lemos ${ }^{1}$, Flávia Martins de Souza ${ }^{1}$, Kíria Karolline Gomes Moreira ${ }^{1}$, Tiago Pereira Guimarães ${ }^{1}$, Marcela Luzia Rodrigues Pereira ${ }^{2}$, Sérgio Fernandes Ferreira ${ }^{2}$, Rodrigo Medeiros da Silva ${ }^{2}$

${ }^{1}$ Mestrando do programa de pós graduação em Ciência Animal da EVZ/UFG. Email: barbaralemos@zootecnista.com.br

${ }^{2}$ Doutorando do programa de pós graduação em Ciência Animal da EVZ/UFG.

\section{Resumo}

Objetivou-se apresentar conhecimentos técnicos e científicos relacionados com a suplementação de rebanhos de cria e recria de bovinos de corte em pastejo. A suplementação alimentar consiste na correção de nutrientes limitantes á produtividade animal. O ponto mais importante é garantir disponibilidade de forragem. Para vacas de cria o monitoramento da condição corporal auxilia nas decisões de quando e quanto suplementar. Em relação aos bezerros, a partir da $9^{a}$ semana de vida somente o leite não supre a demanda de energia e após a $15^{a}$ semana a proteína também passa a ser limitante para o desempenho. Na recria de fêmeas, o ganho em peso satisfatório antes da estação de monta é fundamental para se obter um maior número de novilhas púberes aptas a ficarem prenhes. De forma geral, durante a seca é importante suplementação múltipla com elevada concentração de proteína degradada no rúmen (PDR), na transição seca/águas é interessante diminuir o teor de PDR e energia do 
LEMOS, B.J.M. et al. Suplementação de bovinos de corte em pastejo. PUBVET, Londrina, V. 6, N. 32, Ed. 219, Art. 1457, 2012.

suplemento, uma vez que a forragem nova apresenta alta fração solúvel. No período das águas os animais respondem positivamente a suplementação com alto teor de proteína não degradável no rúmen e durante a transição águas/seca é importante aumentar o aporte de nitrogênio e energia no ambiente ruminal.

Palavras-chave: bezerros, novilhas, novilhos, suplementos, vacas

\title{
Supplementation of grazing beef cattle
}

\begin{abstract}
The objective was to provide technical and scientific knowledge related to the supplementation of grazing beef cattle. Supplemental feeding is the correction of limiting nutrients to the animal productivity. The most important point is to ensure availability of forage. For beef cows, the monitoring the body condition assists in decisions of when and how much supplemental. The calves from the $9^{\text {th }}$ week of life only the milk do not meet the energy demand and after the $15^{\text {th }}$ week the protein also becomes a limiting factor for performance. For growing heifers, weight gain satisfactory before the breeding season is crucial to achieving a greater number of pubertal heifers able to become pregnant. In general, during the dry season is important multiple supplementation with high concentration of protein degraded in the rumen (RDP), on the transition dry/water is interesting to decrease the content of RDP and energy of the supplement, since the new forage is highly soluble. In the rainy, animals respond positively to supplementation with protein undegradable high and during the transition water/dry is important increase the supply of nitrogen and energy in the rumen.
\end{abstract}

Keywords: calves, heifers, steers, supplements, cows 
LEMOS, B.J.M. et al. Suplementação de bovinos de corte em pastejo. PUBVET, Londrina, V. 6, N. 32, Ed. 219, Art. 1457, 2012.

\section{Introdução}

A suplementação envolve o fornecimento de nutrientes com objetivo de corrigir as deficiências nutricionais apresentadas pelos volumosos. Estratégias adequadas para suplementar animais em pastejo na época seca devem preconizar o atendimento das exigências dos animais através do aumento do consumo e digestibilidade do pasto e não diretamente através da ingestão do suplemento (SOUZA, 2007). A suplementação nas águas e períodos de transição pode melhorar o desempenho individual dos animais, aumentar a taxa de lotação dos pastos, aumentar a produção total por unidade de área e favorecer o desempenho dos animais (SANTOS et al., 2007).

A competitividade do sistema, bem como a permanência do produtor na atividade a longo prazo, depende da estabilidade produtiva durante 0 ano. 0 que permite o planejamento adequado das ações, desenvolvimento de estratégias eficazes diante de anormalidades e, principalmente, poder de negociação para comercializar a produção em épocas favoráveis. Em sistemas eficientes de cria e recria de bovinos de corte mantidos em pastagens tropicais deve-se complementar as exigências nutricionais dos animais, corrigindo deficiências advindas da produção estacional e variação qualitativa das forragens.

Objetivou-se com esta revisão apresentar conhecimentos técnicos e científicos relacionados com a suplementação de rebanhos de cria e recria de bovinos de corte mantidos em pastejo no Brasil.

\section{Suplementos e suplementação}

Suplemento é a mistura composta por ingredientes ou aditivos, podendo conter veículo ou excipiente, que deve ser fornecida diretamente aos animais ou ser indicada para diluição, para melhorar o balanço nutricional (MAPA, 2012a).

Sob o aspecto nutricional a suplementação alimentar seria compensar a carência de e/ou complementar a disponibilidade de matéria seca 
LEMOS, B.J.M. et al. Suplementação de bovinos de corte em pastejo. PUBVET, Londrina, V. 6, N. 32, Ed. 219, Art. 1457, 2012.

potencialmente digestível (MSpd), associada à correção de nutrientes limitantes á produtividade animal (PAULINO et al., 2010a).

Os suplementos podem ser de pronto uso, quando se apresenta pronto para ser fornecido ao animal e para mistura, quando deverá ser misturado ao cloreto de sódio (sal comum) ou a outros ingredientes (MAPA, 2012b).

Técnicos têm denominado os suplementos minerais protéico energéticos de misturas múltiplas, sendo balanceadas para atender a uma determinada demanda de ganho de peso vivo durante todo o ano. Portanto, atendem múltiplas deficiências nutricionais (proteína, energia e minerais) do animal em pastejo (S'THIAGO, 2012).

As bactérias que degradam fibras são sensíveis à ausência de nitrogênio (N) no líquido ruminal, que deve ser mantido no mínimo a $10,70 \mathrm{mg} / \mathrm{dL}$ (LAZZARINI et al., 2009) ou alterações no pH do meio, $\mathrm{pH}$ abaixo de 6,2 podem limitar seu crescimento. A redução da disponibilidade de $\mathrm{N}$ é conseqüência da redução no teor de $\mathrm{PB}$ na pastagem durante a época seca. A redução no $\mathrm{pH}$ do meio é conseqüência direta da rápida degradação do amido presente em maior quantidade nos alimentos concentrados.

Desta forma, é importante analisar cuidadosamente estes dois aspectos, para que as respostas esperadas com a suplementação sejam satisfatórias (S'THIAGO, 2012). De acordo com SOUZA (2007) a suplementação exclusiva com carboidratos causa efeitos deletérios sobre a utilização da FDN da forragem. Desta forma, ocorre a redução da utilização do pasto como fonte de energia para o animal.

\section{Suplementação de bovinos de corte em pastejo}

O ponto mais importante para o sucesso da suplementação é o manejo da pastagem, garantindo disponibilidade de forragem. Associado a este está o uso de animais especializados dentro de cada raça, eficientes na conversão de alimentos em produto dentro do sistema de criação. 
LEMOS, B.J.M. et al. Suplementação de bovinos de corte em pastejo. PUBVET, Londrina, V. 6, N. 32, Ed. 219, Art. 1457, 2012.

O consumo de forragem de animais em pastejo é afetado por fatores inerentes ao animal, como sexo, peso e composição corporal, nível de produção e potencial genético (NRC, 1996) e fatores relacionados à pastagem, como a disponibilidade de forragem, a estrutura do pasto, a composição bromatológica da forragem e finalmente a suplementação ou não com alimentos concentrados (AGOSTINHO NETO, 2010).

Bovinos criados em pastagens caminham grande parte do dia colhendo forragem e apresentam gasto extra de energia, o que pode aumentar suas exigências nutricionais se comparados a animais em confinamento (MORAES et al. 2009).

A suplementação tem como finalidade a exploração do potencial genético animal, visando alcançar o máximo de rendimento econômico, diminuindo a oscilação no desempenho animal conforme a disponibilidade de nutrientes na pastagem (ACEDO et al., 2011).

A suplementação múltipla fornece diversos nutrientes como minerais, vitaminas, proteínas, energia e aditivos, que podem ser palatabilizantes, melhoradores da eficiência alimentar, aminoácidos, bem como produtos relacionados com a sanidade animal. A viabilidade econômica da suplementação depende de fatores como o custo dos insumos, ganho extra obtido, preço pago pelo produto final e efeito sobre a lotação dos pastos.

Vários fatores que interferem na resposta animal à suplementação com concentrado ainda não são totalmente compreendidos, tais como: alterações nas exigências de manutenção do animal em função do maior ou menor tempo de pastejo, assim como em função das alterações na eficiência de uso dos nutrientes ingeridos, alterações no consumo e digestibilidade da forragem em relação aos parâmetros ruminais como $\mathrm{pH}$, concentração de $\mathrm{N}-\mathrm{NH}_{3}$ e taxa de passagem; fontes e doses dos suplementos em relação á quantidade e oferta de forragem (AGOSTINHO NETO, 2010).

Conhecidas as exigências dos animais, o primeiro ponto a ser avaliado para suplementar bovinos em pastejo é a qualidade do volumoso. Características que permitam descrever a estrutura do pasto são relevantes na 
LEMOS, B.J.M. et al. Suplementação de bovinos de corte em pastejo. PUBVET, Londrina, V. 6, N. 32, Ed. 219, Art. 1457, 2012.

avaliação de pastagens porque influenciam o comportamento ingestivo, a digestibilidade e o desempenho dos animais e permitem avaliar a qualidade da forragem (SCHIO et al., 2011).

Na Tabela 1 está apresentada a composição bromatológica média (\%) de pastos do Gênero Brachiaria em função de diferentes períodos de coleta durante o ano. Pode-se considerar que outras forrageiras tropicais apresentam comportamento semelhante, sendo fundamental identificá-las para o balanceamento da dieta dos animais em pastejo.

TABELA 1 - Composição bromatológica média (\%) de pastos do Gênero Brachiaria em função de diferentes períodos de coleta durante o ano

\begin{tabular}{lcccc}
\hline \multirow{2}{*}{ Parâmetros } & \multicolumn{4}{c}{ Períodos $^{1}$} \\
\cline { 2 - 5 } & Seca-Águas $^{2}$ & Águas & Águas-seca & Seca \\
\cline { 3 - 5 } Proteína Bruta & 7,16 & 9,66 & 8,39 & 5,07 \\
Fibra em Detergente Neutro & 67,30 & 70,08 & 70,26 & 73,43 \\
$\begin{array}{l}\text { Fibra em Detergente Neutro } \\
\text { indigestível }\end{array}$ & 18,80 & 10,73 & ----- & 39,56 \\
$\begin{array}{l}\text { Lignina } \\
\text { Proteína Insolúvel em }\end{array}$ & 8,55 & 7,00 & 9,13 & 8,35 \\
$\begin{array}{l}\text { Detergente Neutro } \\
\text { Proteína Insolúvel em }\end{array}$ & 36,17 & 39,42 & 45,22 & 43,92 \\
Detergente Ácido & 9,41 & 5,42 & 7,35 & 13,63 \\
\hline
\end{tabular}

${ }^{1}$ Seca-Águas: entre Setembro e Novembro; Águas: entre Dezembro e Fevereiro; Águas-Seca: entre Março e Maio; Seca: entre Junho e Agosto. ${ }^{2}$ Amostras obtidas via simulação do pastejo animal e extrusa esofágica.

Fonte: Adaptado de PAULINO et al. (2002)

A estacionalidade de produção de forragem durante o período seco representa uma das maiores limitações da estabilidade da produção ao longo do ano. É caracterizada por intensa redução na produção de forragem e, consequentemente, na produção animal.

Em função da ocorrência de variação sazonal e anual, o diferimento do pasto, isoladamente, não seria suficiente. Assim, a suplementação volumosa 
LEMOS, B.J.M. et al. Suplementação de bovinos de corte em pastejo. PUBVET, Londrina, V. 6, N. 32, Ed. 219, Art. 1457, 2012.

pode ser requerida, devendo ser fornecida estrategicamente. É interessante que a suplementação priorize o uso de produtos regionais menos onerosos (PAULINO et al., 2010a).

Segundo AGOSTINHO NETO (2010) em média animais em pastejo não suplementados com fontes energéticas apresentam ganho de peso médio diário (GPD) de $0,72 \mathrm{Kg} \mathrm{cab}^{-1}$, enquanto que os animais suplementados com doses entre 0,2 a 0,6\% do PV apresentam GPD de 0,92 $\mathrm{kg} \mathrm{cab}^{-1}$. Quanto á suplementação protéica e protéico energética, em média os animais não suplementados apresentam GPD de $0,744 \mathrm{~kg} \mathrm{cab}^{-1}$ contra $0,818 \mathrm{~kg} \mathrm{cab}^{-1}$ dos animais suplementados com doses entre 0,15 a 1,0\% do PV. No entanto, sabese que a eficiência da suplementação energética depende de um elevado teor de PB do pasto, o que não é característica de grande parte das forragens tropicais.

\section{Fase de cria de bovinos de corte}

A fase de cria representa a base da cadeia produtiva. Desta forma, as ações sobre ela refletem diretamente sobre todo o segmento da carne bovina.

O Brasil, de 2007 a 2011, tem produzido em média 49 milhões de bezerros por ano (USDA, 2011). As maiores atividades pecuárias estão localizadas na região centro-oeste que responde por $29,8 \%$ dos bezerros produzidos no Brasil (MILLEN et al., 2011).

No Brasil Central, o nascimento de bezerros ocorre entre agosto e outubro, provenientes de uma estação de monta de novembro a janeiro, e a desmama ocorre entre fevereiro e abril, por volta dos 6 a 7 meses de idade (S'THIAGO, 2012).

A duração da temporada reprodutiva pode ser considerada um reflexo da tecnificação e gerenciamento do sistema de produção (MORAES et al., 2007). O estabelecimento da estação de monta é feito gradativamente ao longo de três anos para se ter uma estação bem definida de apenas três meses, sendo conduzida na época do ano com maior disponibilidade de forragem. 
LEMOS, B.J.M. et al. Suplementação de bovinos de corte em pastejo. PUBVET, Londrina, V. 6, N. 32, Ed. 219, Art. 1457, 2012.

É importante que o período de acasalamento tenha uma duração em torno de 90 dias, permitindo maior uniformidade dos bezerros (idade e peso), o que otimiza estratégias visando redução da mortalidade e aumento do peso à desmama, bem como permite disciplinar um calendário de atividades durante o ano. Além disso, permite o planejamento para que o período de maior requerimento nutricional das vacas (início da lactação) coincida com o de maior oferta de alimentos.

O índice médio do intervalo de partos (IP) dos rebanhos nacionais de cria é de 21 meses, o ideal seria de que a fêmea produza um bezerro por ano, ou seja, um IP de 12 meses (EUCLIDES FILHO \& EUCLIDES, 2010). Biologicamente os baixos índices reprodutivos decorrem principalmente dos efeitos combinados da condição nutricional deficiente devido á baixa oferta de forragens e as maiores exigências nutricionais decorrentes do terço final da gestação e da amamentação (MORAES et al., 2007).

\section{Condição corporal de vacas reprodutoras}

A nutrição e reprodução são ciências complementares. A estimativa da condição corporal das vacas é uma medida subjetiva para classificar os animais em função da cobertura muscular e de gordura. Nas últimas décadas foram propostos critérios com cinco, seis, oito, nove e até dez classes, gerando dificuldade para comparações e uso efetivo nos sistemas de produção (MORAES et al., 2007). Entretanto, o NRC (1996) recomenda a escala de 1 a 9 pontos, em que a vaca com escore de condição corporal (ECC) 1 encontra-se debilitada e a fêmea com ECC 9 está extremamente gorda.

Esta é uma informação importante para contribuir na tomada de decisão de quando desmamar, quando e quanto suplementar as vacas de corte, visando reduzir o período de anestro pós-parto (MORAES et al., 2007).

O ECC é um bom indicador do status energético da vaca de corte e a variação da condição corporal altera a exigência de energia para mantença de vacas adultas (EUCLIDES FILHO \& EUCLIDES, 2010). O ponto chave não é o 
LEMOS, B.J.M. et al. Suplementação de bovinos de corte em pastejo. PUBVET, Londrina, V. 6, N. 32, Ed. 219, Art. 1457, 2012.

conhecimento de que a condição corporal afeta a fertilidade, mas sim, o uso da informação com a finalidade de melhorar o nível nutricional das vacas mais necessitadas (MORAES et al., 2007).

\section{Suplementação de vacas reprodutoras}

A nutrição adequada das vacas reprodutoras é um dos fatores que mais contribui para o aumento da eficiência produtiva dos rebanhos de cria.

Níveis de PB na dieta abaixo dos recomendados, durante os períodos pré e pós-parto, afetam negativamente o desempenho reprodutivo de vacas de corte com bezerro ao pé (PEIXOTO \& OSÓRIO, 2007). Portanto, é muito importante a ingestão de níveis adequados de PB no final da gestação e no início da lactação. Para rebanhos em pastejo, a utilização de mistura mineral com uréia ou uma fonte de proteína verdadeira (farelo de soja ou farelo de algodão) e uma fonte de energia (milho moído) configura uma boa estratégia para assegurar a ingestão mínima de PB durante períodos em que a forragem disponível é de baixa qualidade.

PEIXOTO et al. (2006), suplementando vacas Charolês, Nelore e seus cruzamentos no pós-parto com concentrado protéico com inclusão de uréia, constataram que vacas suplementadas com farelo de trigo e uréia apresentaram teor de nitrogênio ureico sérico (NUS) superior aos das não suplementadas e ao das suplementadas somente com farelo de trigo $(18,19$ vs 14,54 e $12,48 \mathrm{mg} \mathrm{dL}^{-1}$, respectivamente). Não foi verificada interação entre suplementação e grupo genético das vacas.

Os teores de nitrogênio ureico do leite (NUL) não diferiram $(P>0,05)$ entre tratamentos. A taxa de gestação das vacas não foi influenciada pelos teores de NUS e NUL nem pela suplementação.

PEIXOTO et al. (2006) não encontraram diferença na taxa de gestação de vacas com nível de uréia sérica superior ou inferior a $15 \mathrm{mg} \cdot \mathrm{dL}^{-1}(52,00 \mathrm{vs}$. $57,38 \%$, respectivamente), demonstrando que o teor de uréia sérica não 
LEMOS, B.J.M. et al. Suplementação de bovinos de corte em pastejo. PUBVET, Londrina, V. 6, N. 32, Ed. 219, Art. 1457, 2012.

interfere no desempenho reprodutivo de vacas de corte, nas condições do seu experimento.

\section{Suplementação de bezerros de corte}

A quantidade e o valor nutritivo do leite são muito importantes nos primeiros meses de vida do bezerro e também quando este passa a ingerir alimentos sólidos. A Tabela 2 contém informações acerca da composição média do leite de vacas Nelore nos seis meses após o parto.

TABELA 2 - Composição média do leite de vacas Nelore no período de 0 a 180 dias de lactação

\begin{tabular}{ll}
\hline Itens & $0-180$ dias \\
\hline Energia Líquida (Mcal/Kg) & $0,75 \pm 0,01$ \\
Proteína Bruta (\%) & $3,71 \pm 0,20$ \\
Gordura (\%) & $3,88 \pm 0,06$ \\
Lactose (\%) & $4,74 \pm 0,04$ \\
Extrato Seco (\%) & $13,31 \pm 0,21$ \\
\hline
\end{tabular}

Fonte: PAULINO et al. (2010b)

Entre os 3 e 4 meses de idade o bezerro se transforma em um animal ruminante funcional. Esse período coincide com a redução da produção de leite da vaca, colocando o bezerro em situação desfavorável, uma vez que o leite e o pasto podem não satisfazer às exigências do animal para seu pleno desenvolvimento (PORTO et al., 2009a).

A relação entre ganho de peso médio diário (GMD) do bezerro e a produção de leite da vaca diminui 16 semanas após o nascimento. Portanto, o uso de suplementos pode ser necessário nessa fase da vida do animal, quando se deseja obter altas taxas de ganho (PORTO et al., 2009a).

Considerando a energia e proteína como os nutrientes mais limitantes ao desenvolvimento dos animais, nota-se na Tabela 3 que a partir da 9a semana de vida (63 dias de idade), somente o leite não supre toda a energia 
LEMOS, B.J.M. et al. Suplementação de bovinos de corte em pastejo. PUBVET, Londrina, V. 6, N. 32, Ed. 219, Art. 1457, 2012.

necessária para que o bezerro ganhe em torno de 800 gramas por dia (PAULINO et al., 2010b). A partir da $15^{a}$ semana a proteína também passa a ser limitante para o desempenho dos lactentes.

TABELA 3 - Disponibilidade de energia metabolizável (EM) e proteína metabolizável (PM) via leite, exigências de EM e PM totais para mantença e ganho de peso de bezerros Nelore lactentes e necessidades de leite (NL) para atender ás exigências de EM dos bezerros, de acordo com a semana de lactação $(\mathrm{SL})$ e peso dos animais $(\mathrm{Kg})$

\begin{tabular}{ccccccc}
\hline SL & $\begin{array}{c}\text { Peso } \\
\text { bezerro }\end{array}$ & $\begin{array}{c}\text { EM via } \\
\text { Leite }\end{array}$ & $\begin{array}{c}\text { PM via } \\
\text { leite }\end{array}$ & EMt & PMt & NL \\
\hline 1 & 35,6 & 4,63 & 160,71 & 2,91 & 154,87 & 3,98 \\
2 & 41,20 & 4,85 & 168,06 & 3,25 & 156,79 & 4,45 \\
3 & 46,80 & 5,01 & 173,63 & 3,58 & 158,65 & 4,89 \\
4 & 52,40 & 5,12 & 177,72 & 3,90 & 160,49 & 5,32 \\
5 & 58,00 & 5,21 & 180,59 & 4,20 & 162,29 & 5,75 \\
6 & 63,60 & 5,26 & 182,46 & 4,50 & 164,09 & 6,16 \\
7 & 69,20 & 5,29 & 183,54 & 4,80 & 165,87 & 6,56 \\
8 & 74,80 & 5,30 & 183,97 & 5,09 & 167,66 & 6,95 \\
9 & 80,40 & 5,30 & 183,88 & 5,37 & 169,44 & 7,34 \\
10 & 86,00 & 5,29 & 183,39 & 5,65 & 171,23 & 7,72 \\
15 & 114,00 & 5,12 & 177,65 & 6,98 & 180,34 & 8,09 \\
\hline
\end{tabular}

Fonte: PAULINO et al., 2010b.

\section{Creep-feeding}

O uso da alimentação suplementar do bezerro durante o aleitamento é denominado creep-feeding. Essa técnica veio adaptada da criação artificial de bezerras leiteiras, em que é fornecido leite de forma controlada, concentrado e volumoso de boa qualidade visando tornar a bezerra um ruminante funcional 
LEMOS, B.J.M. et al. Suplementação de bovinos de corte em pastejo. PUBVET, Londrina, V. 6, N. 32, Ed. 219, Art. 1457, 2012.

em pouco tempo e independente do leite materno (EUCLIDES FILHO \& EUCLIDES, 2010).

Para bovinos de corte a técnica se desenvolve em uma instalação denominada creeper, que consiste de um cercado em que apenas as crias têm acesso. Devendo possibilitar ao bezerro alimentação suplementar com quantidades crescentes de concentrado, acrescido da amamentação livre e acesso a pastagem com boa oferta de forragem (EUCLIDES FILHO \& EUCLIDES, 2010).

O sistema de creep-feeding é utilizado com o propósito de fornecer alimento suplementar aos bezerros a partir dos 3 meses de idade, para aumento do peso à desmama. $\mathrm{O}$ alimento utilizado nessa fase deve apresentar bom valor nutritivo e ser palatável para favorecer o consumo (PORTO et al., 2009a).

COUTO (2008) verificou que o uso da suplementação múltipla em diferentes níveis, contendo $100 \mathrm{~g}$ de PB, comparado a animais recebendo apenas mistura mineral, não promove melhorias significativas no desempenho de bezerras de corte lactentes sob pastejo em Brachiaria decumbens Stapf suplementadas em sistema creep-feeding durante o período de transição águas/seca.

PORTO et al. (2009a) avaliando diferentes fontes de energia em suplementos isonitrogenados (150 g de PB/animal/dia) fornecidos a bezerros Nelore verificaram que animais alimentados com grão de milho e sorgo triturado apresentaram desempenho superior àqueles que receberam apenas mistura mineral e farelo de arroz como fonte de energia. Machos utilizam melhor os nutrientes da dieta em comparação às fêmeas, o que pode interferir na relação custo/benefício da dieta fornecida. PORTO et al. (2009a) explicam que isso ocorre provavelmente pela ação da testosterona, promovendo maior deposição proteica, com efeitos mínimos sobre a deposição lipídica, o que interfere na composição do ganho em peso.

Nitrogênio uréico do sangue (NUS) e albumina sérica são os principais metabólitos utilizados para monitorar o status nutricional protéico 
LEMOS, B.J.M. et al. Suplementação de bovinos de corte em pastejo. PUBVET, Londrina, V. 6, N. 32, Ed. 219, Art. 1457, 2012.

em bovinos (PEIXOTO et al., 2006). PORTO et al. (2009a) relatam que os níveis séricos de nitrogênio ureico (NUS) são afetados pelo nível nutricional, caracterizando um indicador sensível e imediato da ingestão de proteína. PORTO et al. (2009a) recomendam a associação de milho e sorgo como fontes energéticas na formulação de suplementos múltiplos para bezerros lactentes, ressaltando que o uso de suplemento múltiplo contendo milho como única fonte de amido diminui o consumo de pasto (Tabela 4).

TABELA 4 - Médias e coeficientes de variação (CV) para os consumos de nutrientes em $\mathrm{g} / \mathrm{kg}$ PV de cada suplemento para as classes de sexo

\begin{tabular}{|c|c|c|c|c|c|c|c|c|}
\hline & \multicolumn{5}{|c|}{ Suplemento } & & & \multirow{2}{*}{$\mathrm{CV}(\%)$} \\
\hline & MM & GM & FTGM & FA & GMS & Machos & Fêmea & \\
\hline MS & 19,4 & 18,9 & 20,5 & 26,3 & 26,3 & $20,3 b$ & $24,3 a$ & 28,3 \\
\hline MS do pasto & $17,1 a b$ & $15,0 b$ & $18,5 a b$ & $21,9 a b$ & $22,5 a$ & $17,3 b$ & $20,7 a$ & 29,4 \\
\hline MO & 18,8 & 18,8 & 20,2 & 25,6 & 25,5 & $20,1 b$ & $23,4 a$ & 27,2 \\
\hline MO do pasto & $15,8 a b$ & $13,7 b$ & $16,9 a b$ & $20,0 a$ & $20,6 a$ & $15,8 b$ & $19,0 a$ & 29,1 \\
\hline FDN & $11,4 a b$ & $10,1 \mathrm{~b}$ & $12,4 a b$ & $14,8 a$ & $15,3 a$ & $11,6 b$ & $14,0 a$ & 29,5 \\
\hline FDNi & $2,2 a b$ & $1,9 b$ & $2,3 a b$ & $2,8 a$ & $2,9 a$ & $2,2 b$ & $2,7 a$ & 29,6 \\
\hline NDT & $13,5 a b$ & $12,9 b$ & $14,0 a b$ & $18,7 a$ & $17,4 a b$ & 14,4 & 16,2 & 28,7 \\
\hline
\end{tabular}

Médias na linha, seguidas por letras diferentes, diferem $(P<0,10)$ pelo teste Tukey. $\mathrm{MM}=$ mistura mineral; $\mathrm{GM}=$ grão de milho triturado; FTGM = farelo de trigo e grão de milho triturado; FA = farelo de arroz; GMS = grão de milho e sorgo triturados.

Fonte: Adaptado de PORTO et al. (2009a).

COUTO (2008) ressalta que a alta concentração de carboidratos não fibrosos (CNF) na dieta propicia a multiplicação de microrganismos não fibrolíticos, em detrimento áqueles que degradam fibras ("efeito carboidrato"), fato agravado pela redução da concentração de proteína á medida que se eleva o nível de suplementação, visto que estes microrganismos concorrem pelo nitrogênio presente no meio.

\section{Creep-grazing}

Uma vez que bezerros jovens realizam alta seletividade do pasto (COUTO, 2008) a técnica de creep-grazing consiste na formação de uma 
LEMOS, B.J.M. et al. Suplementação de bovinos de corte em pastejo. PUBVET, Londrina, V. 6, N. 32, Ed. 219, Art. 1457, 2012.

pastagem de alto valor nutritivo, dentro do pasto das vacas, cercada com 3 fios de arame, mantendo $80 \mathrm{~cm}$ de altura do solo (EUCLIDES FILHO \& EUCLIDES, 2010). Dessa forma, os bezerros tem acesso ilimitado á área de melhor valor nutritivo, retornando para suas mães.

Dentro creep-grazing pode haver cocho coberto com concentrado de creep-feeding, o que acelera o desenvolvimento dos bezerros (EUCLIDES FILHO \& EUCLIDES, 2010). No entanto, esta técnica ainda é pouco difundida no Brasil.

\section{Recria de Bovinos de Corte}

A fase de recria de bovinos de corte envolve a criação dos animais após a desmama realizada em média aos 7 meses de idade. Sendo uma prática tradicional na produção de carne bovina brasileira, geralmente, constitui a fase mais longa do ciclo de produção.

Estratégias para reduzir a duração da fase de recria incluem o pastejo intensivo durante todo o ano e suplementação concentrada durante a estação seca, quando a produção de massa de forragem é extremamente reduzida e os animais normalmente perdem peso, se não forem suplementados com fontes de energia e proteína (MILLEN et al., 2011).

Em propriedades que realizam as atividades de cria e recria ou ciclo completo, geralmente, após a desmama os machos recebem maior atenção tendo acesso a pastagens com melhor oferta de forragem, para serem vendidos como bois magros ou terminados para abate.

Esta prática inadequada prejudica o desenvolvimento das novilhas resultando em atraso na idade ao primeiro acasalamento (NEVES et al., 2009), que preferencialmente deve ocorrer entre 15 e 18 meses de idade. Isto representa uma das principais causas da baixa eficiência produtiva de grande parte dos rebanhos de cria. Uma vez que a média nacional de idade á primeira cria é de 48 meses, enquanto que o ideal seria de no máximo aos 30 meses (EUCLIDES FILHO \& EUCLIDES, 2010). 
LEMOS, B.J.M. et al. Suplementação de bovinos de corte em pastejo. PUBVET, Londrina, V. 6, N. 32, Ed. 219, Art. 1457, 2012.

A idade à puberdade de novilhas está relacionada á sua idade cronológica e também com sua condição fisiológica. Normalmente, melhores desempenhos de animais para reprodução são acompanhados de melhor condição corporal propiciando às fêmeas maiores condições de concepção à cobertura (COUTO, 2008). Nas criações extensivas de bovinos de corte o peso corporal considerado ideal para novilhas ao primeiro acasalamento é de aproximadamente $65 \%$ do peso adulto das vacas para raças zebuínas e $60 \%$ para taurinas (MORAES et al., 2007).

Suplementação de novilhas de corte

Antes do início da primeira temporada de acasalamento, as novilhas de reposição encontram-se em uma das etapas mais onerosas do ciclo de produção, visto que esta categoria não está produzindo (bezerro) e tem grandes exigências nutricionais para seu crescimento (SILVA et al., 2005).

Economicamente é importante que as novilhas entrem em reprodução o mais cedo possível. Desta forma, a nutrição influencia diretamente no aparecimento da puberdade. Assim, o ganho em peso satisfatório antes da estação de monta é fundamental para se obter um maior número de novilhas púberes aptas a ficarem prenhes. Para adotar a suplementação alimentar dos animais é fundamental compreender a interação entre os componentes dos suplementos (proteínas e carboidratos), podendo ser determinante para a melhoria dos índices reprodutivos.

SOUZA (2007) ao estudar a suplementação com compostos nitrogenados e/ou carboidratos de novilhas alimentadas com forragem tropical de baixa qualidade verificou efeito de interação $(P<0,10)$ entre proteína e carboidratos sobre as excreções urinárias de nitrogênio total e ureico, sobre as concentrações de nitrogênio ureico no soro (NUS) e nitrogêncio aminiacal ruminal (NAR) e sobre a eficiência de síntese microbiana. Constatou também que a suplementação exclusivamente protéica elevou em 14,8\%, enquanto a suplementação exclusiva com carboidratos reduziu em $32,5 \%$ as estimativas da taxa ponderada de degradação da FDN. 
LEMOS, B.J.M. et al. Suplementação de bovinos de corte em pastejo. PUBVET, Londrina, V. 6, N. 32, Ed. 219, Art. 1457, 2012.

No trabalho conduzido por VALENTE et al. (2011) novilhas suplementadas na estação seca apresentaram maior ganho médio diário (GMD), evidenciando o efeito linear positivo dos níveis de suplementação múltipla sobre o GMD. Não houve diferenças significativas entre o GMD dos animais alimentados com suplementos múltiplos ou sal nitrogenado. A suplementação aumentou o consumo e digestibilidade de nutrientes, exceto para a digestibilidade da FDN. A suplementação aumentou a produção de nitrogênio microbiano, bem como as perdas de nitrogênio na urina, embora a quantidade de nitrogênio assimilado por bactérias, proporcionalmente ao consumo, foi maior.

COUTO et al. (2010) estudando a suplementação de novilhas com fontes de energia amilácea ou fibrosa durante a estação seca, constataram que o ganho médio diário de peso foi maior nos animais sob suplementação que naqueles que receberam apenas mistura mineral $(0,198$ contra 0,077 $\mathrm{Kg} /$ animal/dia). Além disso, o desempenho dos animais sob suplementação com fonte amilácea foi maior em relação ao daqueles que receberam suplemento à base de farelo de trigo $(0,232$ contra $0,163 \mathrm{~kg} /$ animal/dia $)$. 0 consumo de matéria seca de pasto foi menor no grupo que recebeu o maior nível de suplementação, sendo que o índice de substituição foi de $-0,72$ para os animais suplementados com $0,5 \mathrm{~kg}$ de suplemento/animal/dia contra 0,48 para os animais suplementados com 1,0 kg de suplemento/animal/dia.

SCHIO et al. (2011) trabalhando com novilhas Nelore de $146 \mathrm{~kg}$ de peso corporal (PC) suplementadas (0,25\% PC) em pastejo de Brachiaria brizantha cv. Marandu durante a seca e transição seca/águas, constataram que a utilização de ofertas de forragem variando de 5 a 20\% não influenciaram a digestibilidade e o consumo de nutrientes $(p>0,05)$. Sendo que o melhor ganho médio diário foi para a oferta de forragem de $20 \%\left(0,37 \mathrm{~kg} \mathrm{dia}^{-1}\right)$. A oferta de $20 \mathrm{~kg}$ MS $100 \mathrm{~kg} \mathrm{PC}^{-1}$ proporciona melhor desempenho, devido ao maior ganho médio diário e ganho de peso total. No entanto, os animais submetidos a menores ofertas apresentaram melhores ganhos por área, por sua maior pressão de pastejo, ou maior número de animais por hectare. 
LEMOS, B.J.M. et al. Suplementação de bovinos de corte em pastejo. PUBVET, Londrina, V. 6, N. 32, Ed. 219, Art. 1457, 2012.

COUTO (2008) verificou que o uso da suplementação múltipla com diferentes perfis protéicos não melhora o desempenho de novilhas de corte sob pastejo de Brachiaria decumbens Stapf. suplementadas no período de transição seca/águas. Em seu trabalho não houve diferença no ganho médio diário e peso vivo final entre os animais suplementados e não suplementados $(P>0,10)$. Foi constatado efeito linear decrescente no ganho em peso dos animais com o aumento do nível de NNP $(P<0,10)$, ou seja, quanto maior o teor de nitrogênio de origem não protéica no suplemento menor o ganho médio diário das novilhas.

Durante o período das águas COUTO (2008) verificou correlação positiva entre o consumo de suplemento e ganho médio diário de peso. Desta forma, o nível de suplementação a ser adotado para fêmeas de corte sob pastejo durante a estação das águas deve ser função exclusiva do custo dos recursos empenhados visto que o desempenho é aumentado linearmente com os níveis de suplementação.

Suplementação de novilhos de corte

Em sistemas de alimentação exclusivamente a pasto com suplementação mineral, são comercializados animais mais velhos, principalmente porque os animais ganham peso durante a estação chuvosa (águas) e perdem peso corporal durante a estação seca (MILLEN et al., 2011).

No trabalho conduzido por MORAES et al. (2010) os animais sob suplementação apresentaram maiores exigências de proteína degradável no rúmen, em virtude do maior consumo de energia em comparação àqueles sem suplementação. Por outro lado, as exigências de PNDR foram maiores nos animais sem suplementação.

As maiores exigências de proteína bruta foram observadas para os animais sob suplementação em relação àqueles que não receberam suplemento para qualquer faixa de peso. De forma geral, à medida que o animal cresce, as exigências de PNDR reduzem (MORAES et al., 2010). 
LEMOS, B.J.M. et al. Suplementação de bovinos de corte em pastejo. PUBVET, Londrina, V. 6, N. 32, Ed. 219, Art. 1457, 2012.

Em um trabalho com animais Nelore, não castrados, com média de nove meses de idade e peso corporal de $168 \mathrm{Kg}$, de agosto a novembro, no estado da Bahia, MATEUS et al. (2011) verificaram efeito quadrático para o consumo de MS da forragem, GMD, GPT e peso corporal final, bem como aumento linear para consumos de PB, CT (carboidratos totais) e NDT, e para o coeficiente de digestibilidade aparente da MS, MO, PB, CT, CNF (carboidratos não fibrosos) e o valor de NDT.

A digestibilidade apresentou efeito linear crescente demonstrando efeitos associativos. O aumento das percentagens do suplemento proporcionou aumentos no consumo de nutrientes, mesmo diminuindo o consumo de forragem. MATEUS et al., 2011 recomendam fornecimento de mistura múltipla de até $0,60 \%$ do peso corporal.

PORTO et al. (2009b) avaliando o desempenho de novilhos mestiços em uma pastagem de Brachiaria brizantha cv. Marandu inferiram que a suplementação proteica durante a estação chuvosa resulta em ganhos extras quando se utilizam pastagens tropicais com aproximadamente $8,99 \%$ de PB. Sendo possível obter resposta dos animais à suplementação de baixo consumo nessa época, quando se utilizam animais com potencial genético.

O uso de mistura múltipla nas águas depende do valor e da disponibilidade das fontes protéicas e energéticas no mercado regional, bem como dos objetivos e metas de cada sistema produtivo.

FERREIRA (2009) encontrou resultados semelhantes, em que a suplementação protéica e energética para novilhos Nelore $x$ Red Angus no período das águas promoveu maiores ganhos em peso. Porém, dependendo do preço da arroba e do consumo do suplemento protéico-energético, essa estratégia pode não apresentar efeito econômico positivo quando comparado a animais mantidos em pastagens de boa qualidade e recebendo apenas suplementação mineral adequada.

ACEDO et al. (2011) avaliando fontes proteicas em suplementos para novilhos em pastagens de Brachiaria decumbens Stapf. durante a transição seca-águas, constataram que os consumos de matéria seca de pasto (MSP) e 
LEMOS, B.J.M. et al. Suplementação de bovinos de corte em pastejo. PUBVET, Londrina, V. 6, N. 32, Ed. 219, Art. 1457, 2012.

matéria orgânica de pasto (MOP) não diferiram $(P>0,10)$ segundo os suplementos. Entre os animais do suplemento a base de grão de milho moído e uréia/sulfato de amônia (MU) o consumo de MS foi maior $(P<0,10)$ que 0 observado para os do grupo-controle. A média de consumo de todos os animais suplementados foi de $21,0 \mathrm{~g}$ de $\mathrm{MS} / \mathrm{Kg}$ de PV, contra os $18,3 \mathrm{~g}$ de $\mathrm{MS} / \mathrm{Kg}$ de $\mathrm{PV}$, verificada entre os animais do tratamento controle.

A suplementação com milho e ureia para novilhos em pastejo em quantidades próximas a $0,17 \%$ do $\mathrm{PV}$, durante a época de transição secaáguas, proporciona maior consumo e digestibilidade aparente total da MS em relação à mistura mineral (ACEDO et al., 2011). Os valores de pH ruminal, Nitrogênio microbiano e a eficiência microbiana não foram influenciados pelos tratamentos, sendo que os valores de $\mathrm{pH}$ mantiveram-se próximos de 6,2, abaixo do qual ocorre a inibição da atividade dos microrganismos fibrolíticos.

Entre os parâmetros da nutrição proteica, a concentração de nitrogênio amoniacal ruminal (NAR) tem sido utilizada como referência à qualidade das condições ruminais para as atividades microbianas, especialmente no que se refere aos microrganismos que degradam carboidratos fibrosos, os quais empregam o NAR como fonte nitrogenada para o crescimento. Níveis deficitários de NAR implicam redução no crescimento microbiano tanto por deficiência direta como por ampliação dos custos energéticos para captação destes compostos no meio (ACEDO et al., 2011).

LAZZARINI et al. (2009) avaliando o consumo, a digestibilidade e a dinâmica de trânsito e degradação de FDN em bovinos alimentados com forragem tropical, encontrou concentração de NAR $10,70 \mathrm{mg} / \mathrm{dL}$, a qual poderia ser interpretada como a concentração mínima necessária para a manutenção adequada da atividade microbiana sobre a FDN da forragem.

No trabalho ACEDO et al. (2011) foram reportados concentrações de NAR superiores a $10,70 \mathrm{mg} / \mathrm{dL}$ para todos os tratamentos, demonstrando que gramíneas tropicais nas águas apresentam quantidades relativamente altas de compostos nitrogenados não proteicos, principalmente nos períodos iniciais de rebrota. No entanto, fica evidente a superioridade dos suplementos protéicos 
LEMOS, B.J.M. et al. Suplementação de bovinos de corte em pastejo. PUBVET, Londrina, V. 6, N. 32, Ed. 219, Art. 1457, 2012.

em relação á mistura mineral quanto á disponibilidade de nitrogênio para o desenvolvimento bacteriano.

Quanto aos valores de síntese e eficiência de utilização de NDT para a produção de proteína microbiana, VALADARES FILHO et al. (2006) recomendam, como referencial teórico, $12 \mathrm{~g} \mathrm{PBmic} / 100 \mathrm{~g}$ de NDT para condições tropicais. Valor bastante próximo dos resultados relatados por ACEDO et al. (2011).

\section{Considerações finais}

De forma geral, na época seca é muito importante suplementação múltipla com elevada concentração de proteína degradada no rúmen (PDR) fornecendo nitrogênio para os microganismos runimais. $\mathrm{Na}$ transição seca/águas, conforme a rebrota do pasto é interessante diminuir o teor de PDR e energia do suplemento, uma vez que a forragem nova apresenta alta fração solúvel.

No período das águas os animais respondem positivamente a suplementação múltipla com alto teor de proteína não degradável no rúmen (PNDR). Na transição águas/seca é importante aumentar o aporte de nitrogênio e energia no ambiente ruminal.

\section{Referências}

ACEDO, T. S.; PAULINO, M. F.; DETMANN, E.; VALADARES FILHO, S. C.; SALES, M. F. L.; PORTO, M.O. Fontes proteicas em suplementos para novilhos no período de transição secaáguas: características nutricionais. Arquivo Brasileiro de Medicina Veterinária e Zootecnia, Belo Horizonte, v. 63, n. 4, p. 895 - 904, 2011.

AGOSTINHO NETO, L. R. D. Estratégias de suplementação energética para bovinos em recria em pastagens tropicais durante as águas e seus efeitos na terminação em confinamento. 2010. 76 f. Dissertação (Mestrado em Ciência Animal e Pastagens) - Escola Superior de Agricultura "Luiz de Queiroz", Piracicaba.

COUTO, V. R. M.; PAULINO, M. F.; DETMANN, E.; VALADARES FILHO, S. C.; SALES, M. F. L.; BARROS, L. V.; PORTO, M. O.; VALENTE, E. E. L. Energy sources and supplementation levels for beef heifers raised during the dry season. Revista Brasileira de Zootecnia, Viçosa, v. 39, n. 11, p. $2494-2501,2010$. 
COUTO, V. R. M. Desempenho e características nutricionais de fêmeas de corte em cria e recria submetidas a diferentes estratégias de suplementação em pastejo. 2008. 97 f. Dissertação (Mestrado em Zootecnia) - Universidade Federal de Viçosa, Viçosa.

EUCLIDES FILHO, K.; EUCLIDES, V. P. B. Desenvolvimento recente da pecuária de corte brasileira e suas perspectivas. In: PIRES, A. V. Bovinocultura de Corte. v. 1. Piracicaba: FEALQ, 2010. p. 11 - 38.

FERREIRA, S. F. Suplementação protéico energética para novilhos Nelore $\mathbf{x}$ Red Angus criados em sistema de pastejo na época chuvosa. 2009. 38f. Dissertação (Mestrado em Zootecnia). Instituto de Zootecnia, Universidade Federal Rural do Rio de Janeiro, Seropédica.

LAZZARINI, I.; DETMANN, E.; SAMPAIO, C. B.; PAULINO, M. F.; VALADARES FILHO, S. C.; SOUZA, M. A.; OLIVEIRA, F. A. Dinâmicas de trânsito e degradação da fibra em detergente neutro em bovinos alimentados com forragem tropical de baixa qualidade e compostos nitrogenados. Arquivo Brasileiro de Medicina Veterinária e Zootecnia, Belo Horizonte, v. 61, n. 3, p. 635 - 647, 2009.

MAPA, Ministério da Agricultura, Pecuária e Abastecimento. Instrução Normativa No 15, de 26 de maio de 2009. Disponível em: http://extranet.agricultura.gov.br/sislegis/action/detalhaAto.do?method=abreLegislacaoFedera $\underline{\text { I\&chave }=50674 \& \text { tipoLegis }=\mathrm{A}}$. Acesso em 18 de março de 2012a.

MAPA, Ministério da Agricultura, Pecuária e Abastecimento. Instrução Normativa No 12, de 30 de novembro de 2004.2 Disponível em: http://extranet.agricultura.gov.br/sislegis/action/detalhaAto.do?method=abreLegislacaoFedera I\&chave $=50674$ \&tipoLegis $=$ A. Acesso em 18 de março de 2012b.

MATEUS, R. G.; SILVA, F. F.; ÍTAVO, L. C. V.; PIRES, A. J. V.; SIVA, R. R.; SCHIO, A. R. Suplementos para recria de bovinos Nelore na época seca: desempenho, consumo e digestibilidade dos nutrientes. Acta Scientiarum, Maringá, v. 33, n. 1, p. 87 - 94, 2011.

MILLEN, D. D.; PACHECO, R. L.; MEYER, P. M.; RODRIGUES, P. H. M.; BENI ARRIGONI, M. Current outlook and future perspectives of beef production in Brazil. Animal Frontiers, Champaign, v. 1, n. 2, p. $46-52,2011$.

MORAES, E. H. B. K.; PAULINO, M. F.; MORAES, K. A. K.; VALADARES FILHO, S. C.; FIGUEIREDO, D. M.; COUTO, V. R. M. Exigências de proteína de bovinos anelorados em pastejo. Revista Brasileira de Zootecnia, Viçosa, v. 39, n. 3, p. 601 - 607, 2010.

MORAES, E. H. B. K.; PAULINO, M. F.; MORAES, K. A. K.; FIGUEIREDO, D. M.; VALAdARES FILHO, S. C.; PAULINO, P. V. R.; COUTO, V. R. M. Exigências de energia de bovinos de corte em pastejo. Revista Brasileira de Zootecnia, Viçosa, v. 38, n. 5, p. 933 - 940, 2009.

MORAES, J. C. F.; JAUME, C. M.; SOUZA, C. J. H. Manejo reprodutivo da vaca de corte. Revista Brasileira de Reprodução Animal, Belo Horizonte, v. 31, n. 2, p. 160 - 166, 2007.

NEVES, F. P.; CARVALHO, P. C. F.; NABINGER, C.; JACQUES, A. V. A.; CARASSAI, I. J.; TENTARDINI, F. Estratégias de manejo da oferta de forragem para recria de novilhas em pastagem natural. Revista Brasileira de Zootecnia, Viçosa, v. 38, n. 8, p. 1532-1542, 2009.

NATIONAL RESEARCH COUNCIL - NRC. Nutrient requirements of beef cattle. 7.ed. Washington, D.C.: National Academy Press, 1996. 242p.

PAULINO, M. F.; DETMANN, E.; VALADARES FILHO, S. C.; SILVA, A. G.; CABRAL, C. H. A.; VALENTE, E. E. L.; BARROS, L. V.; PAULA, N. F.; LOPES, S. A.; COUTO, V. R. M. Bovinocultura programada. In: SIMPÓSIO DE PRODUÇÃO DE GADO DE CORTE, 7., 2010, Viçosa. Anais... Viçosa: SIMCORTE, 2010. p. 281 - 297.a

PAULINO, P. V. R.; FONSECA, M. A.; HENRIQUES, L. T.; VALADARES FILHO, S. C.; DETMANN, E. Exigências nutricionais de vacas e bezerros Nelore. In: VALADARES FILHO, S. C.; 
MARCONDES, M. I.; CHIZZOTTI, M. L.; PAULINO, P. V. Exigências Nutricionais de Zebuínos Puros e Cruzados BR- CORTE, 2 ed., Viçosa: 2010, p. 175-193.b

PAULINO, M. F.; ZERVOUDAKIS, J. T.; MORAES, E. H. B. K.; DETMANN, E.; VALADARES FILHO, S. C. Bovinocultura de ciclo curto em pastagens. In: SIMPÓSIO DE PRODUÇÃO DE GADO DE CORTE, 3., 2002, Viçosa. Anais... Viçosa: SIMCORTE, 2002. p. 153 - 196.

PEIXOTO, L. A. O.; OSÓRIO, M. T. M. Perfil metabólico protéico e energético na avaliação do desempenho reprodutivo em ruminantes. Revista Brasileira de Agrociência, Pelotas, v. 13, n. 3, p. 299 - 304, 2007.

PEIXOTO, L. A. O.; BRONDANI, I. L.; NÖRNBERG, J. L.; RESTLE, J.; ALVES FILHO, D. C.; PAZINI, M.; CORADINI, M. T.; SANTOS, C. V. M. Perfil metabólico protéico e taxas de concepção de vacas de corte mantidas em pastagem natural ou suplementadas com farelo de trigo com ou sem uréia. Ciência Rural, Santa Maria, v. 36, n. 6, p. 1873 -1877, 2006.

PORTO, M. O.; PAULINO, M. F.; VALADARES FILHO, S. C.; DETMANN, E.; SALES, M. F. L.; COUTO, V. R. M. Fontes de energia em suplementos múltiplos para bezerros Nelore em creepfeeding: desempenho produtivo, consumo e digestibilidade dos nutrientes. Revista Brasileira de Zootecnia, Viçosa, v. 38, n. 7, p. 1329 - 1339, 2009a.

PORTO, M. O.; PAULINO, M. F.; VALADARES FILHO, S. C.; SALES, M. F. L.; LEÃO, M. I.; COUTO, V. R. M. Fontes suplementares de proteína para novilhos mestiços em recria em pastagens de capim-braquiária no período das águas: desempenho produtivo e econômico. Revista Brasileira de Zootecnia, Viçosa, v. 38, n. 8, p. 1553 -1 560, 2009b.

SANTOS, F.A.P., COSTA, D.F.A., GOULART, R.C.D. Suplementação de bovinos de corte em pastagens: conceitos atuais e aplicações. In: SIMPÓSIO SOBRE MANEJO DA PASTAGEM, 24., 2007, Piracicaba. Anais... Piracicaba: FEALQ, 2007. p. 273-296.

SCHIO, A. R.; VELOSO, C. M.; SILVA, F. F.; ÍTAVO, L. C. V.; MATEUS, R. G.; SILVA, R. R. Ofertas de forragem para novilhas Nelore suplementadas no período de seca e transição seca/águas. Acta Scientiarum, Maringá, v. 33, n. 1, p. 9 - 17, 2011.

SILVA, M. D.; BARCELLOS, J. O. J. PRATE, E. R. Desempenho reprodutivo de novilhas de corte acasaladas aos 18 ou aos 24 meses de idade. Revista Brasileira de Zootecnia, Viçosa, $v$. 34, n. 6, p. 2057 - 2063, 2005.

SOUZA, M. A. Consumo, digestibilidade e dinâmica ruminal em bovinos alimentados com forragem tropical de baixa qualidade e suplementados com compostos nitrogenados e/ou carboidratos. 2007. 56f. Dissertação (Mestrado em Zootecnia) Universidade Federal de Viçosa, Viçosa.

S'THIAGO, L. R. L. Suplementação de bovinos em pastejo: aspectos práticos para o seu uso na mantença ou ganho de peso. EMBRAPA Gado de Corte. Acesso em 19 de março de 2012. Disponível

em:

http://www.cnpgc.embrapa.br/publicacoes/naoseriadas/suplementhiago/.

USDA. 2011. Livestock and Poultry: World Markets and Trade. United States Department of Agriculture. Acesso em 24 de outubro de 2011. Disponível em: http://www.fas.usda.gov/psdonline/circulars/livestock_poultry.pdf.

VALADARES FILHO, S. C.; PAULINO, P. V. R.; MAGALHÃES, K. A.; PAULINO, M. F.; DETMANN, E.; PINA, D. S.; AZEVẾDO, J. A. G. Tabelas de composição de alimentos e exigências nutricionais de zebuínos: dados brasileiros. In: SIMPÓSIO DE PRODUÇÃO DE GADO DE CORTE, 5., 2006, Viçosa. Anais... Viçosa: SIMCORTE, 2006. p. 47 - 80.

VALENTE, E. E. L.; PAULINO, M. F.; DETMANN, E.; VALADARES FILHO, S. C.; BARROS, L. V.; ACEDO, T. S.; COUTO, V. R. M.; LOPES, S. A. Levels of multiple supplements or nitrogen salt for beef heifers in pasture during the dry season. Revista Brasileira de Zootecnia, Viçosa, $v$. 40, n. 9, p. $2011-2019,2011$. 